\title{
Short Articles \\ The Truth about Our Bones: William Cheselden's Osteographia
}

\author{
ALLISTER NEHER*
}

The Osteographia of William Cheselden (1688-1752) is universally recognized as one of the most important and beautiful books in the British anatomical tradition. ${ }^{1}$ Cheselden had two principal goals in creating the Osteographia: to provide the most accurate study of the human skeleton to date and to create the most attractive atlas of osteology available. By common agreement, he succeeded in providing a contender for both distinctions. Much has been written about the Osteographia and its place in the history of medicine, but little has been written about its engravings, which is surprising given that everyone who discusses the folio comments on their accuracy as illustrations and how striking they are artistically. My purpose in this paper is to begin a discussion of the engravings that at the same time places them within a larger epistemological and artistic context.

Cheselden decided that it would be best to have his artists use a camera obscura to create the initial drawings for Osteographia. This decision would have seemed appropriate to him for a number of reasons bound up with the pursuit of precision and greater visual truth. The first half of the paper is devoted to the creation of the images. The second focuses on them as theoretical objects. In the second half I argue, by building a case on circumstantial considerations, that using a camera obscura creates viewing conditions that realize by analogy certain key doctrines of John Locke's epistemology, and that this could have implicitly, or even explicitly, influenced Cheselden's decision to use one.

Creating a naturalistic representation of a complex object like a skull is a matter of artifice and convention (Figure 1). The principal trick is to render the three-dimensional world of experience-alive with light, colour and texture-into the two-dimensional world of black and white depiction. It is a testimony to the skills of an artist if this can be accomplished without the viewer commenting on the loss. In an engraving the artist creates the image

(C) Allister Neher 2010

* Dr. Allister Neher, Humanities Department, Dawson College, Montreal, Quebec H3Z 1A4, Canada; e-mail: aneher@dawsoncollege.qc.ca

I would like to thank Pamela Miller, Christopher Lyons, Lily Szczygiel and Diane Philip of the Osler Library of the History of Medicine of McGill University for their goodwill, patience and generosity. I have benefited greatly from their expertise and knowledge of their library's impressive collections. I would also like to thank Annette Wickham, research curator for works on paper at the Royal Academy of Arts, London, for her guidance and the many hours that she devoted to sharing the original drawings for Osteographia with me. Maria Stevens also deserves a special thank you for her helpful comments on an earlier version of this paper. I am especially indebted to the Wellcome Trust for a travel award I received in 2009 that allowed me to study first-hand the drawings for the Osteographia at the Royal Academy.

\footnotetext{
${ }^{1}$ William Cheselden, Osteographia, or the anatomy of the bones, London, W Bowyer, 1733.
} 


\section{Allister Neher}

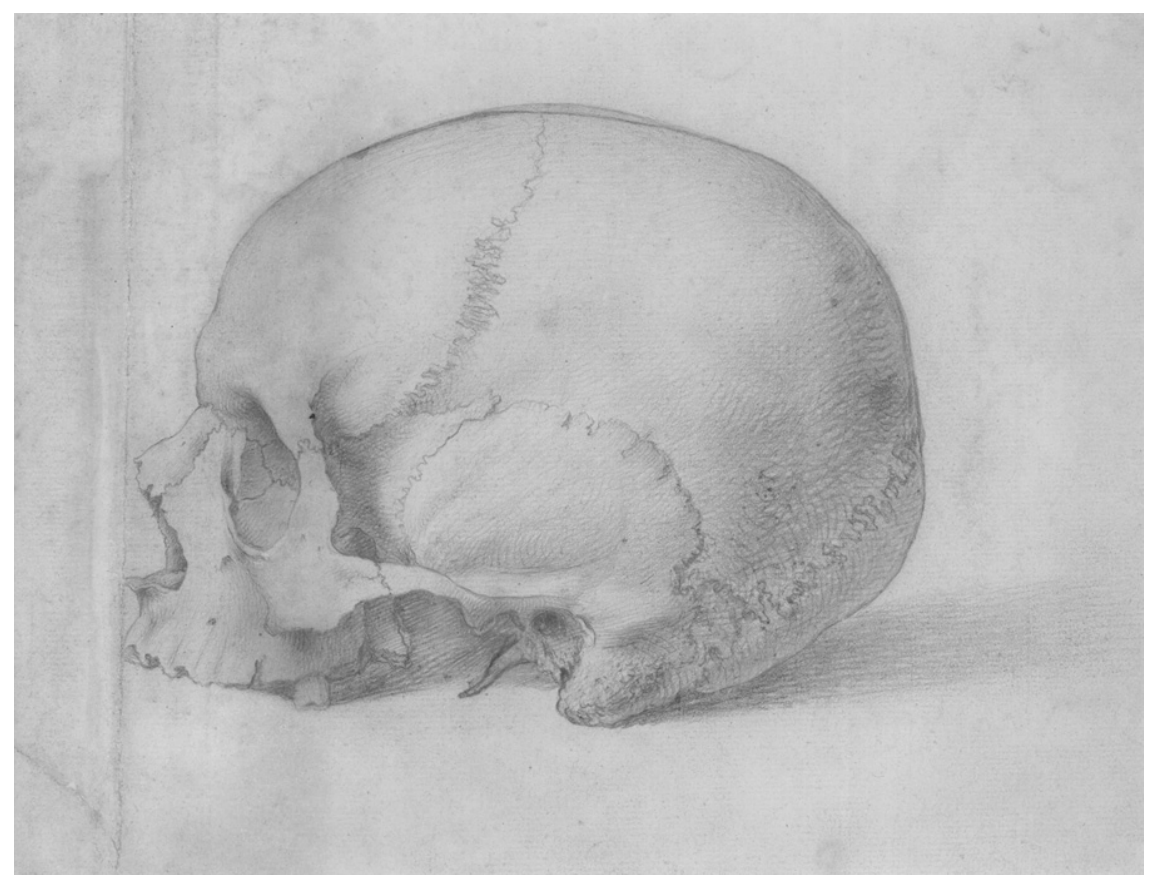

Figure 1: Human skull viewed in profile, by Gerard van der Gucht, 1733 (03/6852). Pencil on laid paper, $20.8 \times 26.2 \mathrm{~cm}$ (Photo credit: () Royal Academy of Arts, London).

with a burin and a metal plate. Once the design is incised into the plate it is covered with ink and the excess ink is wiped off. A piece of paper is then pressed onto the plate and an image is formed by the ink that has remained in the incised grooves. In the end, the artist creates the image solely through the use of line and modelling (shading through the alternation of light and dark to reveal volume and texture) ${ }^{2}$

Drawing a complex object can be a vexing process if one's goal is the greatest possible fidelity. Any image of an object is made from a particular and limited point of view and unavoidably that will present it as foreshortened in some respects. Furthermore, the artist's head will shift in the process of drawing the object and that will modify the manner in which it is foreshortened, which will then create uncertainty about how it should be depicted. Cheselden was aware of the difficulties involved in rendering the complicated three-dimensional forms of the skeleton and attempted to minimize them by having his artists, Gerard van der Gucht (1695/6-1776) and Jacob Schijnvoet (1685-1733), use a

\footnotetext{
${ }^{2}$ In the images he created for Osteographia, Cheselden developed a mixed method of printing, using etching as well as line engraving, in order to create more complex textures. "The expressing of the smoothness of the ends of the bones by engraving with only single lines, while the other parts were all etched,
}

was also my contriving" ('To The Reader', unpaged). In etching, an image is drawn on a metal plate that is covered by an acid-resistant wax. The plate is then dipped in acid and where the wax has been removed the acid eats into the plate and creates lines. 


\section{William Cheselden's Osteographia}

camera obscura to make the initial drawings, which they gladly agreed to do. ${ }^{3}$ As Cheselden tells us in his address 'To The Reader', "My engravers, Mr. Vandergucht and Mr. Shinevoet, not less skilled in drawing than in their own proper art, knew too well the difficulties of representing irregular lines, perspective, and proportion, to despise such assistance, always declaring that it was impossible to do these things so well without."4

The camera obscura appears prominently on the title-page of Osteographia and acts as a kind of symbol and guarantee of verisimilitude. Its implicit claim about the trustworthiness of the images in the folio makes it a fine example of what Martin Kemp has called the "Rhetoric of Reality" (Figure 2). If the reader were inclined to doubt the natural authority of the instrument itself, there was always the rhetorical support lent by the powerful institutions that Cheselden was affiliated with, listed on the title-page, and his splendid engraved dedication to the Queen.

Given the long-standing association between beauty and truth in western aesthetics, artistic sophistication provides another kind of implicit support. Consider the compositional arrangement of the plate displaying the vertebrae of the spine (Figure 3). The bounded surface of a page is a dynamic area. Every element of a composition interacts with every other element in a number of ways that involve visual forces of attraction and repulsion, which are modified by a variety of relations of similarity and difference and many other considerations relevant to compositional unity and sense. Attention to composition is one of the factors that make the plates of Osteographia so attractive. Lining the vertebrae up in two neat, symmetrical rows, as one often sees in anatomical atlases, would have created a tired and lifeless display. The artist has created a more dynamic composition by staggering them in an uneven arrangement that involves a more complicated sense of balance; one can feel the interplay of forces that holds the elements in a charged but stable array. Furthermore, the artist has profitably increased the variety, and the visual information, in the composition by presenting each vertebra from a slightly different perspective. These finely delineated and subtly modelled volumetric studies present a visually engaging work of art, even for someone not interested in anatomy and visual truth.

Cheselden created these beautiful images to provide, as Lorraine Daston and Peter Galison would put it, the "working objects" for the science of osteology. ${ }^{6}$ The objects of any natural scientific inquiry come in such great variety that their particularity needs to be managed by creating standardized working objects that can be taken by the community as representative. Such images can aim at an ideal (as in Albinus' Historia musculorum hominis of 1734) or they can offer generalizations based on other principles. Cheselden's images offer specimens that he, England's top surgeon and anatomist, judged to be the most representative cases. They are condensations of expert judgment, produced life-sized, with the greatest possible

\footnotetext{
${ }^{3}$ Gerard van der Gucht and Jacob Schijnvoet were two Dutch artists working in London. For more information on Schijnvoet, see William Le Fanu, 'Anatomical drawings by Jacobus Schijnvoet', Oud Holland, 1960, 75: 54-8.

${ }^{4}$ Cheselden, op. cit., note 1 above, 'To The Reader', unpaged.

${ }^{5}$ Martin Kemp, 'Temples of the body and temples of the Cosmos: vision and visualization in the Vesalian and Copernican revolutions', in Brian S Baigrie (ed.),
}

Picturing knowledge: historical and philosophical problems concerning the use of art in science, University of Toronto Press, 1996, pp. 40-85. See also Martin Kemp, "“The mark of truth": looking and learning in some anatomical illustrations from the Renaissance and eighteenth century', in W F Bynum and Roy Porter (eds), Medicine and the five senses, Cambridge University Press, 1993, pp. 85-121.

${ }^{6}$ Lorraine Daston and Peter Galison, Objectivity, New York, Zone Books, 2007, pp. 19-26. 


\section{OSTEOGRAPHIA,}

\section{OR THE}

\section{A NATOMY \\ OF THE}

$\mathrm{B}$
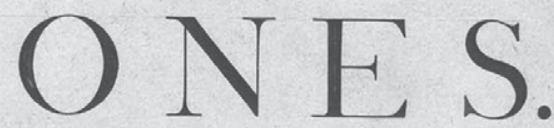

BY WILLIAM CHESELDEN

SURGEON TO HER MAJESTY;

F. R. S.

SURGEON TO S? THOMAS'S HOSPITAL,

AND MEMBER OF THE ROYAL ACADEMY OF SURGERY AT PARIS.

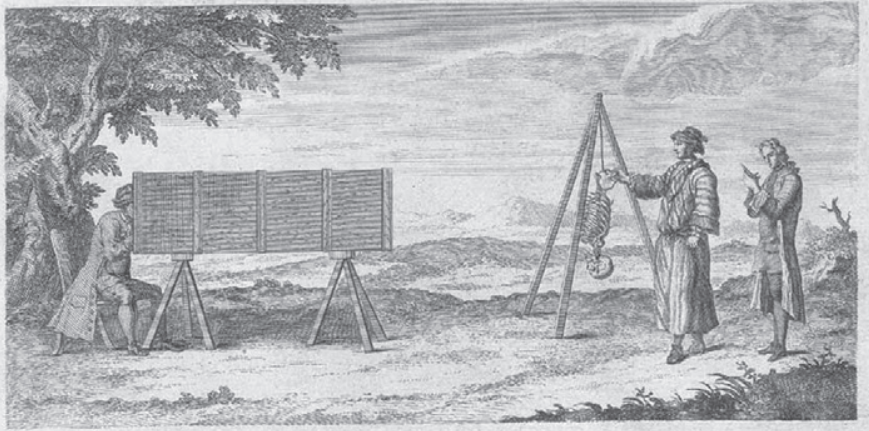

LONDON MDCCXXXIII.

Figure 2: Title-page of Osteographia, engraving (Reproduced by permission of the Osler Library for the History of Medicine, McGill University, Montreal, Canada.) 


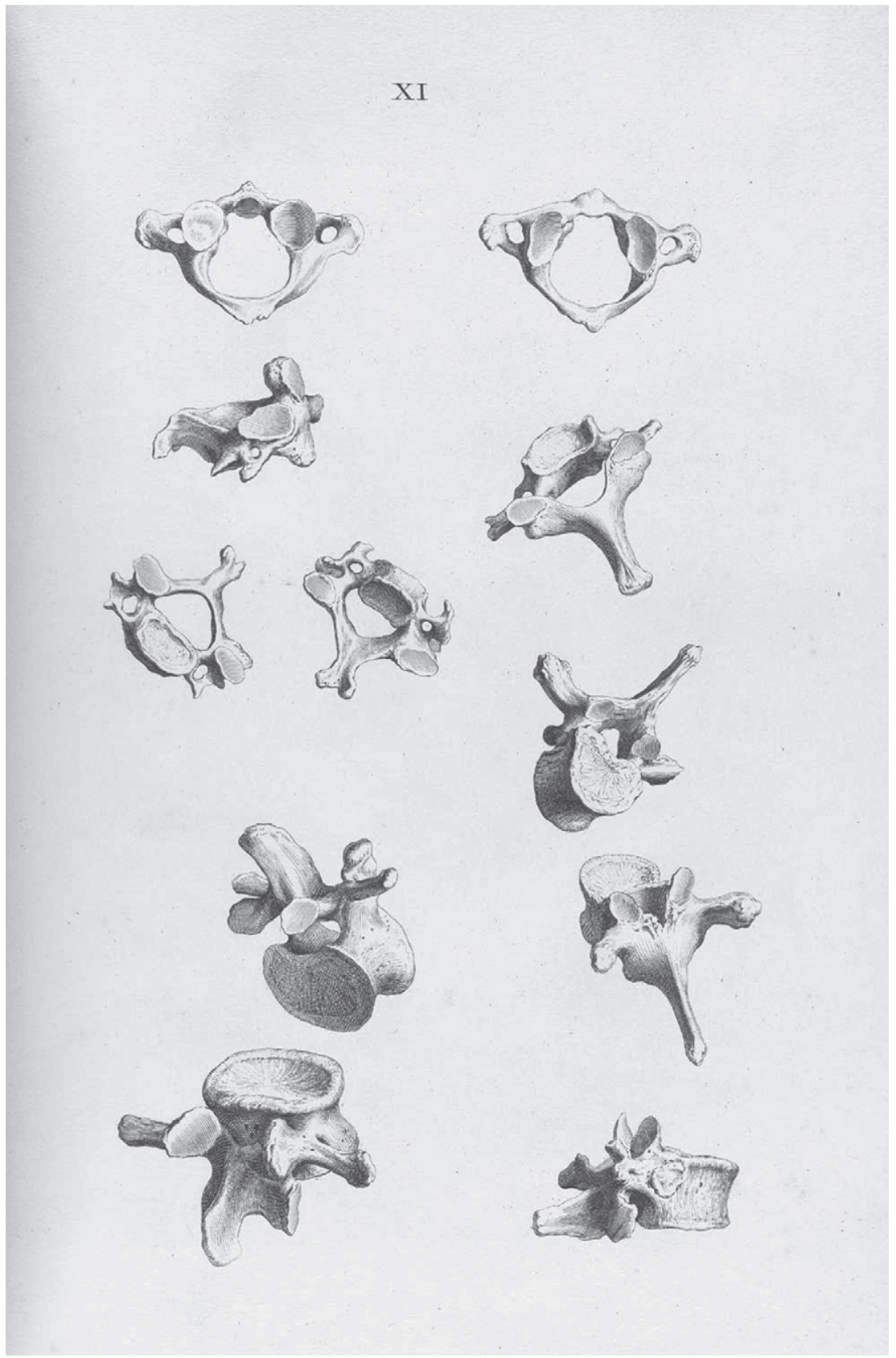

Figure 3: Plate XI from Osteographia, engraving (Reproduced by permission of the Osler Library for the History of Medicine, McGill University, Montreal, Canada.) 


\section{Allister Neher}

care and at significant expense, and presented as the images of record for anatomists and other medical practitioners. In the words of Daston and Galison, they are "reasoned images" whose "truth-to-nature" was assured by Cheselden's reputation and the painstakingly careful process that was used to create them. ${ }^{7}$

Cheselden was probably the first person to use a camera obscura for medical imagery and we believe that the one represented here is of his invention. ${ }^{8}$ The two figures standing beside the artist's easel from which the partial skeleton is suspended are Cheselden's students John Belchier (steadying the skeleton) and Samuel Sharpe (taking notes). We do not know who the figure inside the camera obscura is but it is probably not Cheselden, contrary to what Mark A Sanders has suggested. ${ }^{9}$ The figure is not likely to be Cheselden because he was quite rotund by this date and there is no reason to believe that vanity would have led him to misrepresent his appearance, especially when his face was not visible. More significantly, in my judgment, stylistic analysis strongly indicates that van der Gucht and Schijnvoet made the drawings. ${ }^{10}$ Cheselden himself states in his address 'To The Reader' that the drawings and engravings were done by van der Gucht and Schijnvoet: "Two of the smaller plates, the head of the mantyger, and the sceleton of the tortoise, and all the large plates except viii. xi. xxi. and xxxi. were done by Mr. Gerard Vandergucht ... the rest were performed by Mr. Shinevoet"). If the figure in the camera obscura represents anyone it is probably van der Gucht, as he was the principal artist of the project.

There are, though, three considerations that together might lead someone to conclude that Cheselden was responsible for the drawings. First, there is the fact that Cheselden was a capable draughtsman himself. Second, there is the following intriguing passage about Cheselden's artistic activities in William T Whitley's Artists and their friends in England, 1700-1799: "Early in October 1720 Cheron and Vanderbank opened their Academy in St. Martin's Lane in a great room which had before been used as a meeting house, according to Hogarth, whose name appears this year for the first time in the list of members - another student of 1720 was William Cheselden, the famous surgeon and friend of Pope who said he was 'the most noted and the most deserving man in the whole profession of chirurgery'." 11 Cheselden's biographer, Sir Zachary Cope, conjectures that Cheselden took lessons to improve his skills for the production of Osteographia, but there is no independent evidence to support this. ${ }^{12}$ Cheselden may have wanted to improve his skills so that he could better depict anatomical specimens, that was after all the only means anatomists had to record the results of their dissections, but that does not mean that he did the drawings for Osteographia. Moreover, there were other reasons to take art lessons in eighteenth-century London: artistic sophistication was an important attribute for

\footnotetext{
${ }^{7}$ Ibid., pp. 55-113. See also Claudia Swan, 'Ad vivum, naer het leven, from the life: considerations on a mode of representation', Word and Image, 1995, 11: 353-72.

${ }^{8}$ Cheselden also put a camera obscura on the title-page of his Anatomy of the human body, 13th ed., London, J Dodsley, et al., 1792.

${ }^{9}$ Mark A Sanders, 'Historical perspective: William Cheselden: anatomist, surgeon, and medical illustrator', Spine, 1 Nov. 1999, 24 (21): 2282.
}

\footnotetext{
${ }^{10}$ I have learned in conversation with Annette Wickham (10 January 2009), research curator for works on paper at the Royal Academy of Arts, London, that it is their assessment as well that Cheselden did not do the drawings.

${ }^{11}$ William T Whitley, Artists and their friends in England, 1700-1799, 2 vols, New York, B Blom, 1968, vol. 1, p. 17.

${ }^{12}$ Sir Zachary Cope, William Cheselden 1688-1752, Edinburgh and London, E \& S Livingstone, 1953, p. 67.
} 


\section{William Cheselden's Osteographia}

a gentleman to possess (though no gentleman would want his accomplishments to be compared to those of a commercial draftsman or engraver). The third consideration that might lead someone to believe Cheselden was responsible for the drawings is this statement in his address 'To The Reader': "The actions of all the sceletons both human and comparative, as well as the attitudes of every bone, were my own choice: and where particular parts needed to be more distinctly expressed on account of the anatomy, there I always directed; sometimes in the drawings with the pencil, and often with the needle upon the copper plate, and where the anatomist does not take this care, he will scarce have his work well performed." 13 But we must note that Cheselden says only that he directed the realization of the illustration when needed. He did not do the drawings but instructed his artists on how to make better drawings, if they had not adequately captured the anatomical information he wanted. This is why he chose "the attitudes of every bone." He needed their artistic skills to create images of the highest quality and they needed his anatomical knowledge to understand what they were making images of.

Cheselden has little to say about the design of the camera obscura they used to make the drawings. On page iii of the 'Preface' he remarks that the camera obscura in the image is "such a one as was used in this work". And on the title-page of an undated edition he tells the reader: "The work was executed in a Camera Obscura contrived on Purpose by the Author."14 Happily, Cheselden's student John Belchier (the one steadying the skeleton on the title-page) was more forthcoming about the construction of the device they used. Belchier wrote a review of Osteographia that was published in the Philosophical Transactions of the Royal Society. In it he describes Cheselden's camera obscura in some detail:

It is a long square Tube set upon two Tressels (as represented in the Print before his Book) whose Inside is made black, to prevent the Reflection of Light; towards that End which is nearest the Object, is a Convex Glass placed in a sliding Frame, thro' which the Rays passing from the Object, converge and meet in a Focus upon the Table-Glass placed near the other End, analagous [sic] to the Crystalline Humour and Retina in the Eye.

The Object here represented is the Trunk of a Skeleton fix'd to a Painter's Ezel, which being inverted, appears upright on the Table-Glass, on the rough Side of which the Artist delineates with a Pencil, which afterwards he traces off on Paper. The Convex Glass placed in the sliding Frame being moved backward or forward, makes the Object bigger or less, keeping its due Proportions.

This Camera has several Advantages beyond the common one; for in this, Objects as big as the Life may be taken, or reduced gradually to any Scale; whereas the other only diminishes, and that in a very great Degree. ${ }^{15}$

Belchier's statement that the structure of the camera obscura is "analogous to the Crystalline Humour and Retina in the Eye" provides a useful point of departure for our discussion of the images of the Osteographia and the epistemological framework in which they exist. In choosing the camera obscura as a guarantor of the visual truth of his images he could not have decided upon a more powerful symbol. Indeed, it was the natural one for his era. ${ }^{16}$ In

\footnotetext{
${ }^{13}$ Cheselden, 'To The Reader', unpaged.

${ }^{14}$ The unique copy of this item is in the Hunterian Library, University of Glasgow.

${ }^{15}$ Philosophical Transactions of the Royal Society, Nov. 1733, 38 (430): 196. All the punctuation and spelling is as it is in the original passage.
}

${ }^{16}$ Jonathan Crary, Techniques of the observer, Cambridge, MA, MIT Press, 1990, and Don Ihde, 'Epistemology engines', Nature, 6 July 2000, 406: 21 . 


\section{Allister Neher}

the Essay on human understanding Locke refers to the camera obscura as a model for how knowledge is produced:

... external and internal sensation are the only passages that I can find of knowledge to the understanding. These alone, as far as I can discover, are the windows by which light is let into this dark room. For methinks the understanding is not much unlike a closet wholly shut from light, with only some little opening left to let in external visible resemblances or ideas of things without: would the pictures coming into such a dark room but stay there, and lie so orderly as to be found upon occasion, it would very much resemble the understanding of a man, in reference to all objects of sight, and the ideas of them. ${ }^{17}$

That Locke would have chosen the camera obscura for his epistemological analogy is not surprising, given his medical background and long association with men of science. At Oxford Locke was a member of the experimental philosophy club and had close contact with many individuals who had an active interest in optical instruments and how they could be used to reveal nature's truths. ${ }^{18}$

I would like to argue that in placing his artists in the camera obscura Cheselden might very well have thought that he was sending them into Locke's "dark room" to draw the images that lay on the "tabula rasa" of unmediated human consciousness, as if produced by the "Crystalline Humour and Retina in the Eye" itself. Although Cheselden never openly refers to Locke's theory of knowledge, his approach to making the images fits very well with an approach that could have been taken by someone who was following Locke's philosophy. The main thesis of Locke's Essay on human understanding is that we get all our ideas from experience, either from sensation or reflection. Although there are limits to human understanding we can and do have genuine knowledge of the material world, which is corpuscular and acts on our senses through minute bodies in motion. They act on us by means of those qualities that Locke refers to as primary qualities: solidity, extension, figure, and mobility. These are the qualities that are fundamental to our experience of all matter and inseparable from our understanding of what it is. Primary qualities are distinguished from secondary qualities, such as colour, sound, smell, temperature and taste. Because primary qualities are quantifiable and capable of being expressed mathematically, they are the ones through which science interrogates the world. Secondary qualities are nothing more than powers that bodies have to produce sensations in us; thus they belong to the realm of the personal, while primary qualities exist in the realm of the intersubjectively verifiable. Locke

\footnotetext{
${ }^{17}$ John Locke, Essay on human understanding, abridged and edited by A S Pringle-Pattison, Oxford University Press, 1969, p. 91. The emphasis is Locke's.

${ }^{18}$ To mention only two examples, Locke was a student of Thomas Willis when Christopher Wren was working with Willis and he was familiar with Wren's explorations in astronomy; Locke was also close to Robert Boyle and his principal assistant Robert Hooke, the author of Micrographia. For further discussions of Locke's scientific and medical background, see Maurice Cranston, John Locke, a biography, New York, Macmillan, 1957; Kenneth
}

Dewhurst, John Locke, 1632-1704, physician and philosopher: a medical biography, London, Wellcome Historical Medical Library, 1963; Patrick Romanell, John Locke and medicine: a new key to Locke, Buffalo, NY, Prometheus Books, 1984. Locke maintained an interest in optical instruments, as can be seen in his journals and correspondence from his visits to France, where he always sought out famous instrument makers. See John Locke, Locke's travels in France, 1675-1679, as related in his journals, correspondence and other papers, ed. and intro. by John Lough, Cambridge University Press, 1953. 


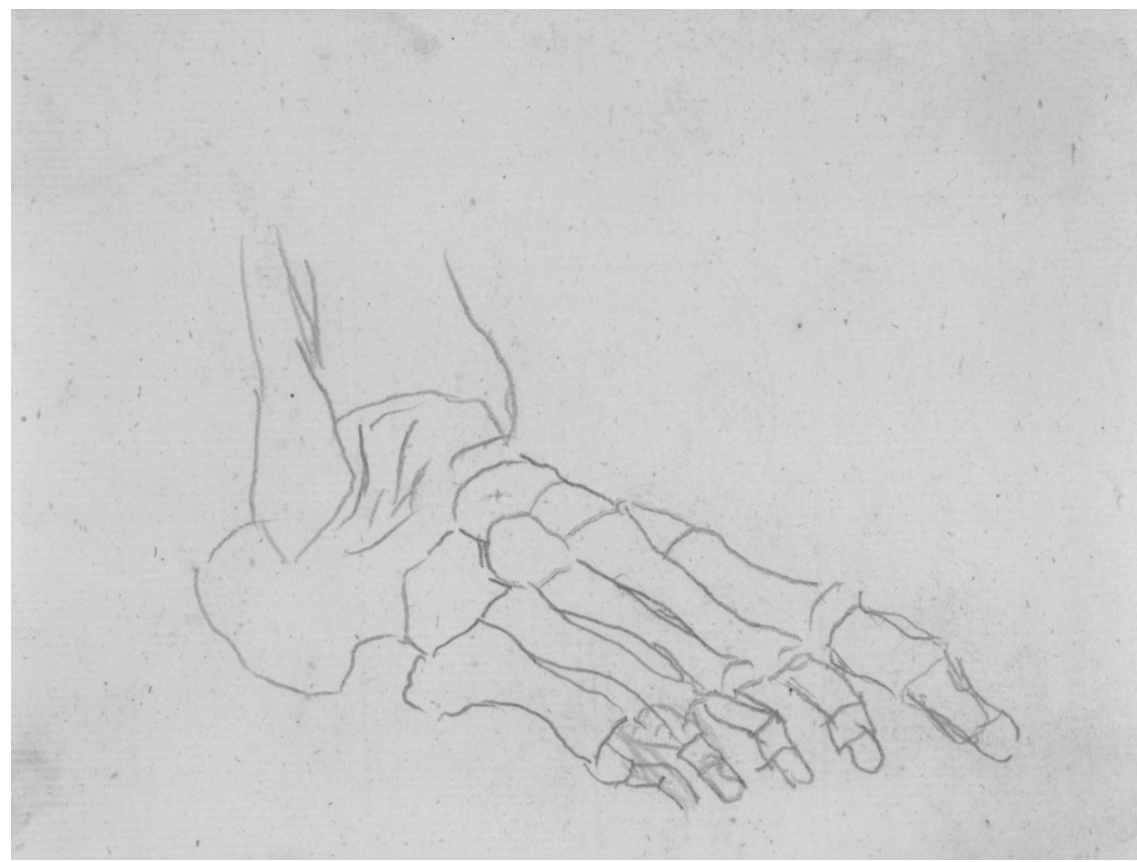

Figure 4: Study of the bones of the foot, by Gerard van der Gucht, 1733 (03/6776). Pencil on cream laid paper, $11 \times 13.3 \mathrm{~cm}$ (Photo credit: @ Royal Academy of Arts, London).

was not the first person to make this distinction, as it was crucial for the development of physics, but it found its proper philosophical formulation in his empiricist epistemology.

In focusing on the volumetric forms of the bones, Cheselden and his artists could avoid distracting and misleading secondary qualities like colour, and make pictures based solely on the quantifiable primary qualities of solidity, extension and figure. Accordingly, all of the properties that Cheselden was interested in conveying were measurable and his results could immediately assume the mantle of science. In concentrating on contour and volume the artists could, so to speak, cut through the unstable secondary qualities of the image in the camera obscura and capture the primary ones waiting there to be recorded. The initial drawings are fascinating because of what they reveal about the artists' attempts to do this. The first step appears to have been to set down straightforwardly and mechanically the contour lines that expressed the boundaries and volumes of the specimens. ${ }^{19}$ Most of them are so light that they cannot be adequately reproduced, though luckily there are some that have been gone over and made a little darker (Figure 4). They are more tracings than drawings and suggest hesitation and uncertainty in determining how the lines should be made. None of van der Gucht's and Schijnvoet's considerable artistic skills are on display. Their hesitation and uncertainty are understandable, though, for not only would they have been labouring to look past the secondary qualities in order to capture the primary ones, but they would also

\footnotetext{
${ }^{19}$ I am using the term "contour line" instead of "outline" because contour
}

lines attempt to suggest volume, threedimensionality. 


\section{Allister Neher}

have been doing that while trying to keep a stable viewing position, so as not to shift the angle of vision and create distortions in the specimen's form. In some drawings their struggles and doubts are recorded in the multiple lines that have been set down to capture a contour. ${ }^{20}$ The initial faint and hesitant sketches appear to have then been built up in stages. In drawings that appear to be the next stage of development, the volumetric outlines are more clearly established and limited modelling has been introduced. Following these there are more artistically elaborate drawings that have been worked up to a state from which one could then produce life-size engravings. As a whole, the set of drawings provides a rare opportunity to watch works of artistic anatomy emerge from simple sketches of medical specimens. It is worth noting that in the production of his "reasoned images"- -his visual generalizations that represent the typical case-Cheselden's approach is in keeping with Locke's account of how general ideas are created: "[I]deas become general by separating from them the circumstances of time and place, and any other ideas that may determine them to this or that particular existence. By this way of abstraction they are made capable of representing more individuals than one." 21 "When therefore we quit particulars, the generals that rest are only creatures of our own making, their general nature being nothing but the capacity they are put into by the understanding of signifying or representing many particulars." 22

The camera obscura gives one the sense of being an interiorized observer on an outside world, and artists' hyper-attentiveness in such singular viewing conditions would have created a unique experience. Thus, phenomenologically it is very unlike being embodied in the world, and this heightens the vibrancy of the experience. Because the image is delimited and its content thereby isolated for observation, its images have a vividness and liveliness that often seems more lifelike than the object or scene in real life: imagine watching the fluttering leaves of a tree in the light of a summer evening as an isolated visual experience. This lent the camera obscura credibility as an instrument of great verisimilitude; and one can understand how it might have appeared to allow its users to isolate and gaze upon the substratum of knowledge, as the microscope, perfected in Locke's era by Antony van Leeuwenhoek and Robert Hooke, allowed its users to isolate and penetrate invisible layers of the visible world. In the eighteenth century, under the sway of Locke's epistemology, it would not have been difficult to believe that in a camera obscura one was in Locke's dark room watching the "external visible resemblances or ideas of things without" fall on the tabula rasa of human understanding and lie there for one's unmediated contemplation and documentation.

I do not want to claim that this is in fact how Cheselden would have articulated his project to his colleagues. Apart from hints in brief statements such as his address 'To The Reader' in Osteographia, we do not know how he would have framed his work in relation to prevalent theories of knowledge, as his papers have not survived. ${ }^{23}$ Given the concordance, though,

\footnotetext{
${ }^{20}$ Royal Academy of Arts (Cab. B/ Box 14, 03/6826). One drawback to using a camera obscura is that the image has a central area of focus and as one moves away from it the image becomes less distinct. This would not have provided a problem for Cheselden because the specimens, even the entire skeleton torso, were small enough to remain in the area of focus.

${ }^{21}$ Locke, op. cit., note 17 above, p. 228.

${ }^{22}$ Ibid., p. 230.
}

\footnotetext{
${ }^{23}$ For example, Cheselden was the first president of the Royal College of Surgeons and yet there is only one original document in their archives directly related to him: the deed of sale of the copyright for Cheselden's Anatomy of the human body to the publishers, Charles Hitch and Robert Dodsley for $£ 200$, dated 8 April 1749. Signed and sealed by William Cheselden, witnessed by James Dodsley.
} 


\section{William Cheselden's Osteographia}

between his approach to making the images for Osteographia and the principal tenets of Locke's Essay, what I do want to suggest is that he could have been working implicitly, or even explicitly, within the framework of Locke's doctrines.

There are other considerations that support the circumstantial case that I have been building. We also know that philosophically Locke was part of the air that Cheselden and his colleagues at the Royal Society breathed. ${ }^{24}$ We also know that Locke was the thinker most revered by his closest artistic friend, Jonathan Richardson, the prominent art theorist. ${ }^{25}$ The most compelling reason, however, to think that Cheselden was well acquainted with Locke's epistemology is that in 1728 he presented to the Royal Society his observations on an extraordinary Lockean experiment that he had performed. ${ }^{26}$ The experiment derived from a problem posed to Locke by William Molyneux and that now bears his name. ${ }^{27}$ The problem had important implications for Locke's theory of knowledge. Molyneux asked if a person who had been born blind, and had learned to identify a sphere and a cube solely by touch, would be able to identify them by vision if he regained his sight. Locke and Molyneux agreed that the answer had to be "no", because the new ideas of sensation that he acquired by vision would not yet have established correspondences with touch; those would have to be created by further experience. This seemed destined to remain a hypothetical problem because blind people simply did not regain their sight, and the medical world was not in a position to help them. Cheselden had developed his skills as an ophthalmic surgeon, however, and had improved techniques for couching cataracts. Around 1726 Cheselden was introduced to a boy of thirteen who had been born with cataracts and was essentially blind, although he could judge variations in the intensity of light. Cheselden successfully couched his cataracts and the boy's descriptions of his experience appeared to prove that Locke and Molyneux were correct. His statements are fascinating:

When he first saw, he was so far from making any judgment about distances, that he thought that all objects whatever touched his eyes (as he expressed it) as what he felt did his skin, and thought no objects so agreeable as those which were smooth and regular, though he could form no judgment of their shape or magnitude; but upon being told what things were, whose form he knew before from feeling, he would carefully observe, that he might know them again; and (as he said) at first he learned to know, and again forgot a thousand things in a day. One particular only, though it may appear trifling, I will relate: Having often forgot which was the cat, and which the dog, he was ashamed to ask; but catching the cat, which he knew by feeling, he was observed to look at her steadfastly, and then, setting her down, said, so puss, I shall know you another time. ${ }^{28}$

It is unlikely, I think, that Cheselden could have undertaken such an experiment and reported it to the Royal Society without being aware of the central doctrines of Locke's

${ }^{24}$ Cheselden became a fellow of the Royal Society in 1712, twenty-one years before the publication of Osteographia. Not only was Locke popular at the Royal Society, the Essay was probably the second most widely read book in England after the Bible. See Kenneth MacLean, John Locke and English literature of the eighteenth century, New Haven, Yale University Press, 1936.

${ }^{25}$ Carol Gibson-Wood, Jonathan Richardson: art theorist of the English Enlightenment, New Haven, Yale University Press, 2000, pp. 78-80.

\footnotetext{
${ }^{26}$ William Cheselden, 'An account of some observations made by a young gentleman, who was born blind, or lost his sight so early, that he had no remembrance of ever having seen, and was couch'd between 13 and 14 years of age', Philosophical Transactions of the Royal Society, 1727-1728, 35 (402): 447-52.

${ }^{27}$ Locke, op. cit., note 17 above, pp. 75-6.

${ }^{28}$ Cheselden, op. cit., note 26 above, p. 448.
} 


\section{Allister Neher}

theory of knowledge and the questions that surrounded them. His friendship with Richardson makes such ignorance doubly unlikely, as Richardson was deeply interested in Locke's epistemology and how it applied to questions of aesthetics. Given their closeness and their common interest in art, it seems improbable that Cheselden could have planned and supervised the production of the prints for Osteographia untouched by Locke's theory of knowledge and unaware of the philosophical significance of using a camera obscura to create the most accurate study of the human skeleton to date and the most attractive atlas of osteology available. 